印尼华语语气词 [méh]调查研究

\title{
Analisis Kata Partikel Modal [méh] dalam Bahasa Tionghoa Indonesia
}

\author{
Elisa Elvaretta; Dr. Herman
}

Universitas Universal

Email: elisaevaretta@gmail.com; hermanuvers72@gmail.com

\begin{abstract}
摘要
印尼华语语气词 [méh] 是印尼华人在沟通交流时较为常用的语气词之一。为了解印 尼华人华语语气词 [méh] 的使用状况、语法特点及其用途, 本文将对此词进行展开研究。 本文以语言学中的词汇学和华语学为理论基础, 使用定性研究法, 通过文献研究法、 问卷调查法、实地观察法和访谈法收集相关资料, 对此词进行调查研究。研究中发现, 印尼华人中有 $82 \%$ 华人说华语是会使用语气词 [méh]，印尼福建华人、客家华人和潮州 华人都会使用此词。此词源于汉语方言的福建话、潮州话和客家话。还有，研究中也 发现, 印尼华语语气词[méh] 是属于疑问词, 可以充当设问句和反问句, 其位置可以在 名词、动词、形容词、代词和助词后面, 是为了表示怀疑、不满意、惊讶和反驳。此 外，影响印尼华人使用此词的因素有语言环境、语言习惯、语言混用和社交媒体。
\end{abstract}

关键词: 印尼华人; 语气词 [méh]; 使用情况; 语法特点

\begin{abstract}
Abstrak
Kata partikel modal [méh] dalam Bahasa Tionghoa Indonesia adalah salah satu kata partikel modal yang sering digunakan oleh orang Tionghoa Indonesia dalam berkomunikasi. Dengan tujuan utama memahami kondisi penggunaan kata partikel modal [méh]pada orang Tionghoa Indonesia dalam berkomunikasi menggunakan bahasa Tionghoa, penelitian ini berdasarkan teori bahasa dan teori bahasa Tionghoa, menggunakan penelitian kualitatif, melalui metode penelitian literatur, metode kuesioner serta metode wawancara untuk mengumpulkan data yang relevan. Hasil penelitian menunjukkan sebanyak $82 \%$ orang Tionghoa Indonesia dalam menggunakan bahasa Tionghua menggunakan kata partikel modal ini, kebanyakan orang Hokkian, orang Tewchew, orang Hakka Indonesia sering menggunakan kata ini, dan fakta juga membuktikan bahwa kata ini berasal dari dialek Minnan, Tewchew, dan dialek Hakka. Dalam penelitian ini juga menunjukan bahwa kata partikel modal [méh] Tionghoa Indonesia merupakan kata tanya, kata ini dapat digunakan sebagai pertanyaan penegas dan pertanyaan retoris, dapat diletakkan setelah kata benda, kata
\end{abstract}


kerja, kata sifat, kata ganti dan kata bantu. Kata ini memiliki fungsi untuk mengungkapkan keraguan, ketidakpuasan, keterkejutan dan menyangkal. Selain itu, lingkungan bahasa, kebiasaan berbahasa, percampuran bahasa serta media sosial menjadi faktor yang menyebabkan orang Tionghoa Indonesia menggunakan kata partikel modal [méh].

Kata kunci: Orang Tionghoa Indonesia; Kata Partikel Modal [méh] Tionghoa Indonesia; Kondisi Penggunaan; Karakteristik Tata Bahasa

\section{一 绪论}

\section{1 研究背景}

印尼华人有悠久的历史, 据史记载, 自汉朝时期已有不少中国人漂洋过海来到印 尼, 大多数来自中国南方, 如: 厦门、泉州、福州、安溪、漳州、梅县、广州、潮州 等。之后, 宋朝时期, 华人到了印尼开始慢慢地形成华人社会, 在印尼定居, 落地生 根，成为印尼华族 ${ }^{1}$ 。印尼华人日常生活中，除了使用印尼语、当地方言、汉语方言沟 通交流外，也有不少说华语。

说起中国话, 世界上至少有五个说法, 即: 中文、汉语、国语、普通话、华语等。 《现代汉语词典》中认为, “汉语” 是汉族的语言, 是以普通话为现代汉语的标准语 ${ }^{2}$, “华语” 是指汉语 ${ }^{3}$, 而普通话是指现代汉语的标准语, 以北京语音为标准音、以北方 话为基础方言、以典范的现代白话文著作为语法规范 ${ }^{4}$ 。此语言, 在中国大陆称之为普 通话，台湾叫做国语与华语，新加坡、马来西亚、印尼称之为 “华语”。

对于华语，李宇明的《大华语：全球华人的共同语》（2017）中认为，华语是汉 民族的共同语在各地区发生变异 ${ }^{5}$ 。郭熙的《华语研究录》的《华语问题答旧金山华文 电视台 “八方论坛” 主持人史东问》中认为，华语不包括汉语方言，它是以普通话为 核心的华人共同语言，是发生变异的。那么汉语是包括方言的，其中之一就是 56 个民 族的汉族人说的话 ${ }^{6}$ 。郭熙也曾说，华语的使用比汉语还要多，华语已经成为全世界华 人社会的通用语。因此，华语就是指全球华人的共同语，尤其在新加坡、马来西亚和 其他有华人社区的国家都使用华语来沟通交流。因为在那些国家的官方语言不一定是

\footnotetext{
《印尼中文报业的历史和前景》. 和平日报，2015-12-02.

2《现代汉语词典》. 商务印书馆. 北京. 2016: 513.

《现代汉语词典》. 商务印书馆. 北京. 2016: 560 .

《现代汉语词典》.商务印书馆. 北京. 2016： 1018.

李宇明. 《大华语: 全球华人的共同语》.北京语言大学, 2017.

${ }^{6}$ 郭熙. 《华语研究录》. 北京. 2012：75.
} 
普通话，所以在这些国家的华语多多少少被这些国家的方言所影响，因此，出生了 “华 语带方言”这种情况。

说起华语，新加坡称之为新加坡华语、马来西亚是马来西亚华语、印尼指印尼华 语。印尼华语是印尼华人也有自己的共同语。在日常生活中，除了说印尼语、印尼当 地方言、汉语方言（闽南话、客家话、广州话）之外，印尼华人也会说华语。以现在 的情况来看，印尼华人说华语时多多少少会被印尼语、印尼当地方言和自己的汉语方 言影响，因此，出生了 “华语带方言与印尼语” 的情况，其中 “语气词”，此语气词 多多少少被方言与印尼语影响。

何为语气词？刘利和李小军的《汉语语气词历时演变的几个特点》中认为：“语 气词是情态类词, 带有言者较多的主观情绪”。胡明扬（1981）认为，“话语中一个 句子表达出来的具体语气，是由句中的语调、词语、语法格式、语气词和语境等诸多 因素共同作用而形成的”。这证明语气词在话语中占重要的身份, 语气词的存在就是 加强说话人的情感态度，因此在沟通交流时才能达到沟通交流的目的。

据调查，在使用华语沟通交流时，印尼华人常用的语气词有 $[k a n] 、[1 e ́ h] 、[1 a h] 、$ [sih]、[méh]、[1oh]等，其中语气词 “[méh]” 印尼华人也常用，目前此词未有研究 者深入研究与探讨, 因此, 为更深入的了解此词的来源、含义、语法、使用者状况等, 本文使用定性研究法对印尼华语语气词 “[méh]”进行展开研究。

虽然有不少研究者研究语气词, 如陈光辉的《现代汉越语语气词对比分析》(2015), 他从语音、句法、语义、语用四个方面对汉语和越语语气词进行对比，他采取中越话 剧剧本来对比出汉语与越语的语气词使用情况, 他使用对比法对两国语言的语气词进 行研究, 但目前未有研究者研究专门研究印尼华语语气词 [méh], 所以本文认为研究此 话题必要并很重要。希望通过此研究可以丰富印尼华语研究, 为研究者介绍印尼华语 语气词、为学者提供宝贵的资料，同时展开印尼华语研究。

\section{2 研究提出}

据调查，在日常生活中，说华语中，印尼华人常用语气词[méh]进行沟通交流，特 别是常用汉语方言的华人。借此机会, 本文对语语气词 [méh]进行研究。在调查中, 本 文发现有几个问题值得探讨，包括：此词源于哪里，影响华人使用此词的原因，此词 的含义，此词的语法结构与功能，使用者的状况等。

\footnotetext{
7 陈光辉. 《现代汉越语语气词对比分析》.福建师范大学, 2015.
} 


\section{3 研究目的和研究意义}

本文以语言学、华语学、词汇学与语法学为理论基础, 通过定性研究法, 使用问 卷调查、访问调查和实地观察本文希望能研究出印尼华语语气词 [méh] 的来源, 了解使 用者的状况，找出影响印尼华人使用此词的因素，分析出此词的含义、语法结构与语 法功能。本文也希望, 通过此研究结果, 可以丰富语言学的内容、可丰富华语研究、 为印尼华语展开研究, 同时也希望, 通过此研究结果可以为研究者和学者提供有价值 的资料，帮助学习者了解印尼华语和印尼华语语气词。

\section{4 研究理论与研究方法}

为更深入的了解语气词 [méh] 的来源、使用者、含义、语法等，本文使用定性研究 法对此话题进行研究，同时使用了文献研究法、访谈法、问卷调查法和统计法对此研 究进行分析与研究。

为丰富资料, 本文收集了相关资料, 查看了《华语研究录》、《印尼语中的单词 构成和单词类简介》 (Introduction to Word Formation and Word Classes in Indonesian) 、 《印尼语法概论》 (Pengantar Tata Bahasa Indonesia) 、 《现代汉 语词汇学教程》、《普通语言学概论》、《语言学概论一一学习指导》、《实用现代 汉语语法》、《现代汉语》, 还有, 阅读了胡明扬的《北京话的语气助词和叹词》、 李云风的《现代汉语语气词 “哦、吆、咯” 的话语功能》、王宏亮的《现代汉语语气 词 “呢”、“吧”、“啊”的比较分析》、习丹丹的《河北唐山方言语气研究》、Wedhawati 的《现代爪哇语法》 (Tata Bahasa Jawa Mutakhir) 、竺家寧的《漢語詞彙學》、金 知妍的《现代汉语句末语气词意义研究》、陈光辉的《现代汉越语语气词对比分析》、 Rochmat Purnomo 的《SMP Negeri 2 Colomadu Kabupaten Karangayar 学校七年级 A 班在 Whatsapp 组群谈话使用的印尼语气词》(Penggunaan Inter jeksi Pada Percakapan di Whatsapp Grup Keluarga VII A SMP Negeri 2 Colomadu Kabupaten Karangayar), 也查看了一些期刊和词典，如：Riki Nasrullah, Dadang Suganda 和 Wagiati 的《印 尼语气词 [Ciye]：形态、句法和语义学研究》（Interjeksi “Ciye” dalam Bahasa Indonesia: Suatu Kajian Morfologi, Sintaksis, dan Semantik) 、刘利和李小军 的《汉语语气词历时演变的几个特点》、王文斌的《从词汇研究走向词汇语义学研究》, 还有，《印尼语大词典第三版》（Kamus Besar Bahasa Indonesia Edisi Ketiga）、 《现代汉语词典》等。 
为更深入了解语气词 [méh] 的来源、使用者、含义与语法, 本文采访了 53 位印尼 华人，包括： 1 位少年 (7 至 17 岁)，49 位青年 (18 至 40 岁)，3 位中年（41-65 岁)， 而老年（66 岁以上）没有采访过，此外，也收集了 97 个问卷调查，此问卷调查是通过 Google form 进行发放, 内容围绕着语气词[méh]。

\section{二 印尼华语语气词 [méh]的使用状况}

庄国土的《论东南亚的华族》中将 “华人” 定义为: 在一定程度上保持中华文化、 具有中国人血缘的非中国公民 ${ }^{8}$ 。我们也可以基于此句话将 “印尼华人” 定为指在一定 程度上保持华人文化、具有华人血脉的印尼籍华人，包括混血华人。从语言上来讲， 印尼华人在不同场合与不同人中会使用华语进行交流，虽然如此，因不同文化背景、 不同语言习惯等，使印尼华人所说的华语产生变化，比如：华人的汉语方言、印尼语、 印尼当地方言等会影响华人说华语, 其中语气词 [méh]。在沟通交流时, 为表达语气、 感情、态度、情绪等华人常用语气词[méh]。下面专门分析使用印尼华语语气词 [méh] 的状况。

\section{1 语气词 [méh]的读音}

从音节上看, 印尼华语语气词[méh]只有一个音节组成的。据《汉语正因教程》中, 音节是有声母和韵母按照一定的规则拼合而成的 ${ }^{9}$ 。从音节上看, 印尼华语语气词 [méh] 是由三个因素组成的, 即 $/ \mathrm{m} / 、 / \mathrm{e} / 、 / \mathrm{h} /$ 。“ $[\mathrm{m}]$ ” 音是属于双唇鼻浊音, “[ée” 音 就像我分发 “诶” 音, 而不是 “鸡” 音, 而 [h] 音是属于押韵。从声调来讲, 印尼华语 语气词 [méh]的声调由两种, 即阴平 (第一声) 和轻声。读此词时, 有时短一些、有时 长一些、有时低一些、有时高一些、有时是轻声, 即是按照语气态度与感情来发, 比 如: 表达疑虑时发又长又比较高的音。

\section{2 使用语气词 $[\mathrm{méh}]$ 的华人}

\section{（一）从身份上看}

为了解谁使用印尼华语语气词 [méh], 本分使用了问卷调查, 通过 Googleform 进 行发问, 收集了 97 个问卷, 包括: 17 位客家华人, 43 位福建华人, 32 位潮州华人, 4 位海南华人和 1 位广东华人, 以下其表:

\footnotetext{
${ }^{8}$ 庄国土.《轮东南亚华族》. 世界民族, 2003：39

${ }^{9}$ 王若江. 《汉语正因教程》. 北京大学出版社, 2005: 7
} 
表 2.1: 问卷调查的印尼华人人数

\begin{tabular}{|c|c|c|c|c|}
\hline & 少年 & 青年 & 中年 & 总数 \\
\hline 客家华人 & 1 & 13 & 3 & 17 \\
\hline 福建华人 & 5 & 37 & 1 & 43 \\
\hline 潮州华人 & 3 & 29 & - & 32 \\
\hline 海南华人 & - & 4 & - & 4 \\
\hline 广州华人 & - & 1 & - & 1 \\
\hline 总数 & 9 & 84 & 4 & 97 \\
\hline
\end{tabular}

从上述表格可看，从客家人中，本文收集了 1 位客家少年、13 位客家青年、3 位 客家中年; 从福建人中，收集了 5 位福建少年、37 位福建青年、1 位福建中年; 从潮 州人中，收集了 3 位潮州少年、 29 位潮州青年，还有 4 位海南青年和 1 位广东青年。

为了了解他们的使用状况, 本文设立一个题目, 即他们说语气词 [méh]的状况, 收 集之后发现，经常用语气词 [méh]的华人有 20 位（21\%），包括：10 位潮州人、8 位福 建人、而客家人有 2 位；偶尔使用者有 59 位（61\%），包括：28 位福建人、18 位潮州 人、9 位客家人、3 位海南人、及 1 位广东人; 而没有用过此词的华人有 18 位 $(18 \%)$ ， 包括： 7 位福建人， 6 位客家人， 4 位潮州人、及 1 位海南人。整体来讲，大多数的印 尼华人在沟通交流时会使用语气 [méh]，从 97 位华人中，有 79 位华人使用 $(82 \%)$, 只不过其使用率高或低罢了，以下其图:

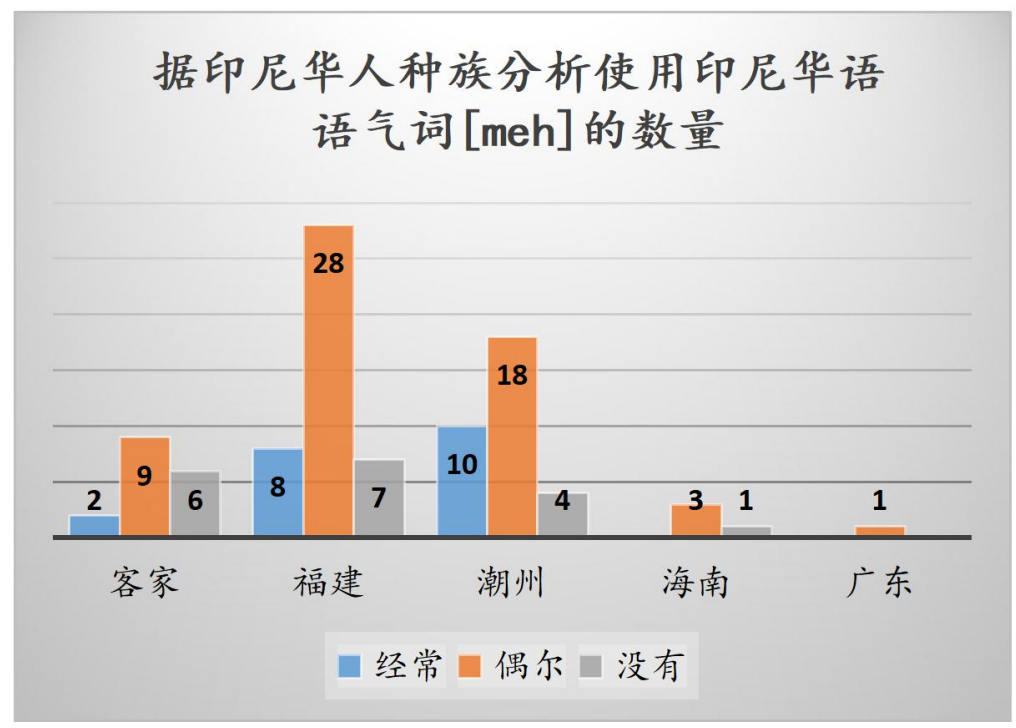

图 2-1 据印尼华人种族分析使用印尼华语语气词 [méh]的数量 


\section{（二）从年龄上看}

从年龄上看, 从 97 位华人中, 经常使用语气词 [méh]的华人共有 20 位, 包括: 2 位 少年、17 位青年、还有 1 位中年; 偶尔使用者共有 59 位, 包括: 6 位的少年、52 位的 青年、还有 1 位的中年; 而没用用过此词的有 18 位，包括: 1 位的少年、15 位的青年、 还有 2 位的中年。据上述资料可看，有 $20 \%$ 经常使用此词， $62 \%$ 偶尔使用， $18 \%$ 没有 使用此词，以下其表:

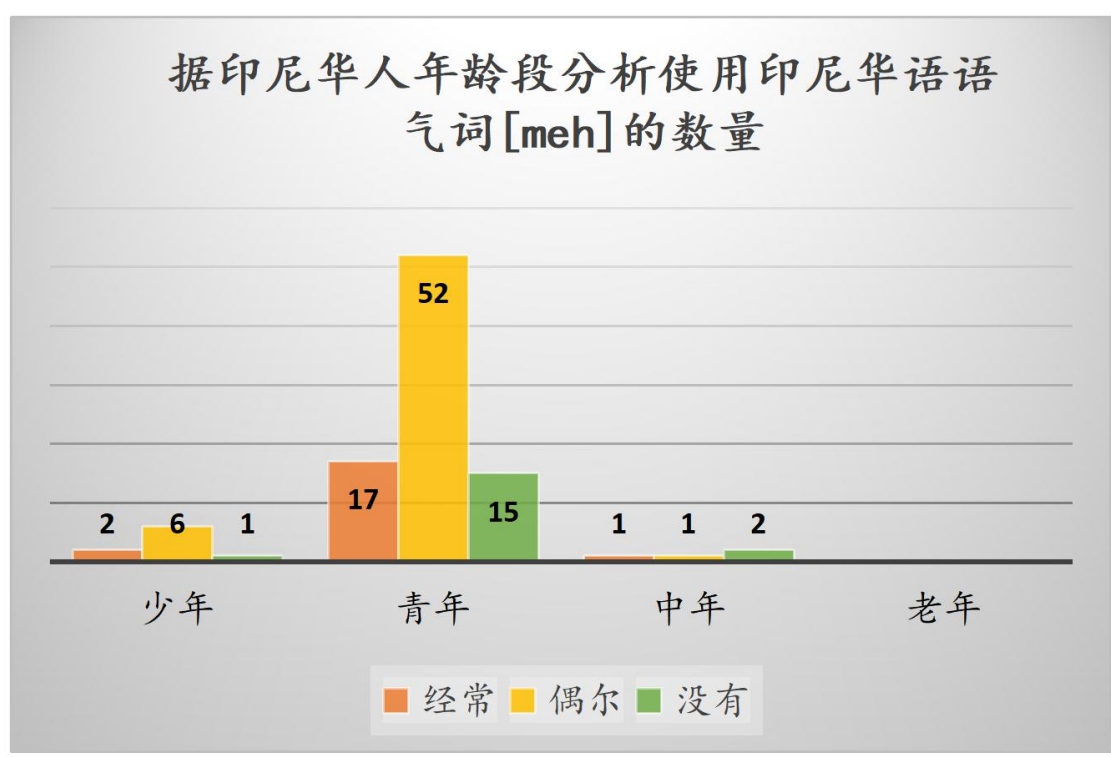

图 2-2 据印尼华人年龄段分析使用印尼华语语气词 [méh]的数量

\section{（三）使用状况}

印尼华人在怎样的情况下使用语气词 $[m e ́ h]$, 也就是说, 华人在什么样的情况下、 在哪里使用此词, 这是本文在此要谈的话题。据资料收集可看，华人使用语气词 [méh] 可分为两个情况，一是，从正式与非正式的场合来看，二是，从无意识与无意识的角 度来看。前者是由环境所造成的情况, 后者是由口头禅习惯造成的情况。

(1) 正式与非正式的场合

据调查发现, 在非正式的情况华人会使用此词, 比如: 朋友之间的交谈时、打电 话、庆祝节日、朋友聚会时、在社交媒体下评论时，华人也会使用此词。举个实例， 两个人在回家的路途上正在谈同班同学的话题, 他们会这样说: “你们仁本来是同班 的呀? ”, 对方回答说: “是啊, 你不知道 [méh]?”。从此例子可看, 他们在交谈时 会使用此语气词。 
此外, 在正式的场合上看, 华人也会使用此词, 比如: 本人上哲学课时, 老师上 《人类生存之路》书的课, 在讲解内容时, 老师也会使用此词表达, 比如: 讲 “时间 的珍贵” 时，老师说：“我们总是忙忙碌碌地过日子，却忽略了我们对家人的关注”， 此时，老师会使用提问的形式发问说: “Memangnya kita tidak bisa luangkan waktu satu dua jam untuk keluarga [méh]?”（译: 难道我们不能抽出一两个小时的时间 来陪我们的父母 [méh]?）。从此例子可得知, 在上课时, 老师也会使用此词。

(2) 无意识与有意识

对于使用者的状况, 调查时, 本文也使用访问法进行调查本, 访问了 53 位华人。 访问中, 我们发现, 在说话时, 他们常用语气词 [méh], 比如: “你知道 [méh]”、“常 用 [méh]”、去巴刹 [méh] 等。但是当我们问他们 “您为什么你会用语气词 [méh]？”， 有些华人会回答说: “我有说吗?”, 也有这样回答: “不知道, 如果没有用它好像 少了些什么。”, 从这里可看, 他们在无意识的情况下会使用此词, 他们使用此词有 时为了强调语气，有时为了回问等。

除了口头交流时华人会使用语气词 [méh], 在文字上也会出现此词, 比如: 在 WhatsApp、Instagram 等, 他们也会使用此词表达, 以下其例:

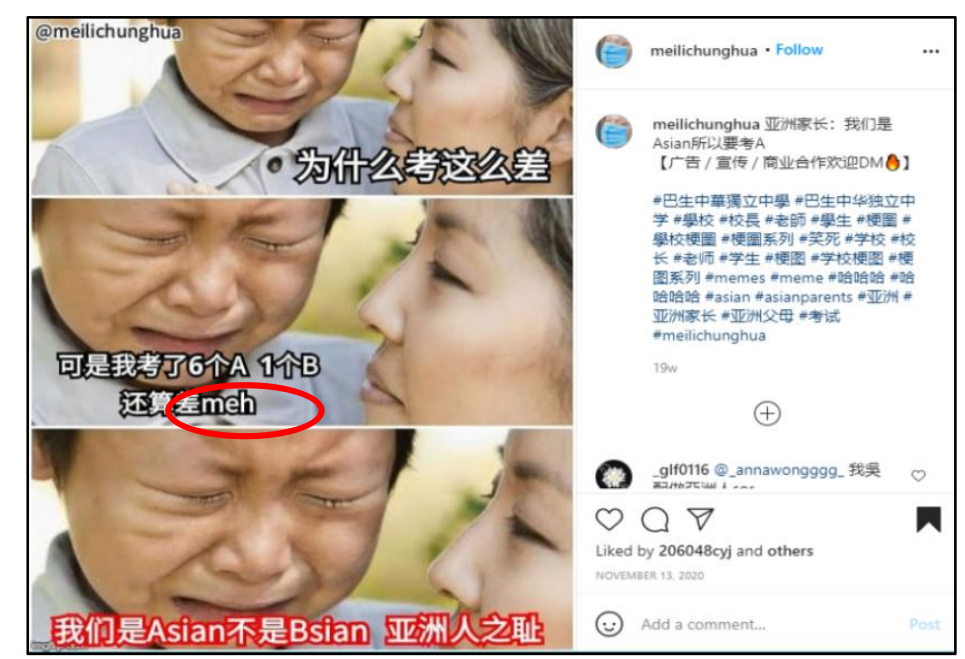

图 2-3 印尼华语语气词 [méh]在 Instagram 社交媒体 @meilichunghua 账户 


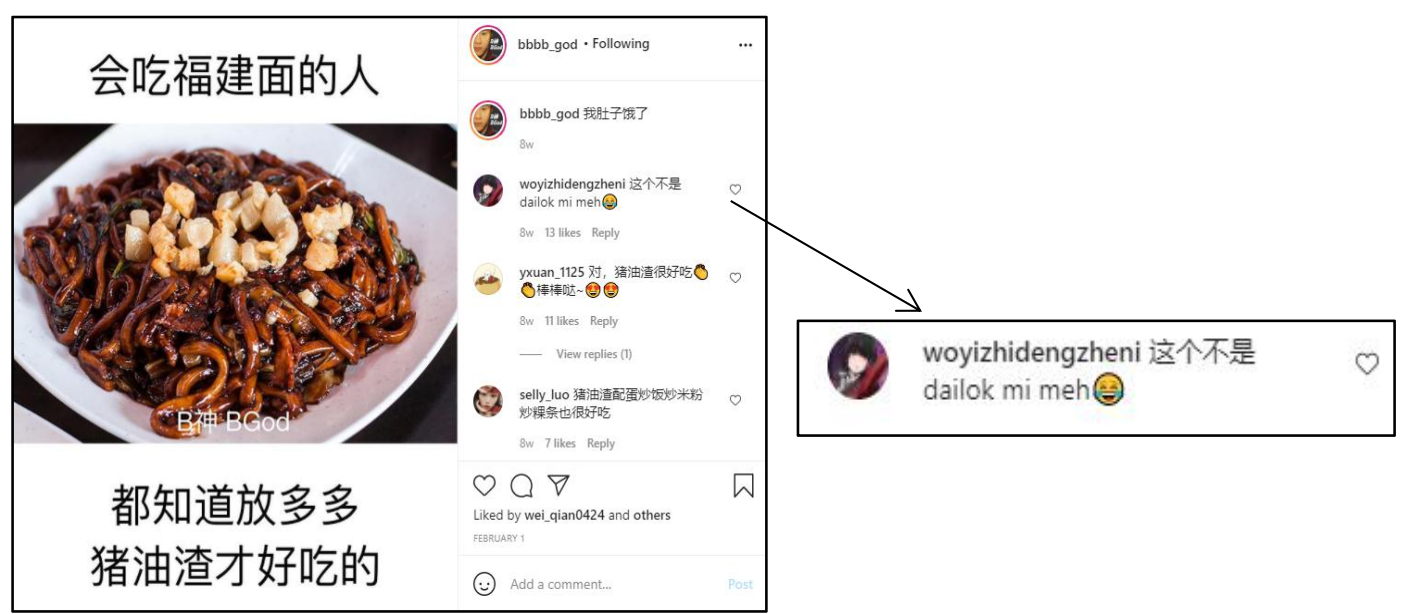

图 2-4 印尼华语语气词[méh] 在 Instagram 社交媒体评论箱

从上图可看，在 Instagram 社交媒体中，包括马来西亚和印尼华人也会使用此词， 如图 2-3 是@meilichunghua 账户所发的帖子, 帖子里面的句子写着 “可是我考了 6 个 A， 1 个 B 还算差 $[\mathrm{meh}]$ ”。图 2-4 是@bbbb_god 账户所发的帖子, 在那帖子的评论箱有 人使用印尼华语语气词 [méh]下评论, 里面写着 “这个不是 dailok mi [meh]”。这说 明，在媒体社交中华人也会使用语气词 [méh]。

\section{三 印尼华语语气词 [méh]的来源、语法特点及其功能}

印尼华语语气词 [méh] 的出现增加了华语词汇方面的新成员，虽然在沟通交流时华 人常用, 但从研究此词方面来看是属于新的话题。下面, 本文谈谈语气词 [méh]的来源、 语法特点语语法功能。

\section{1 语气词 [méh]的来源}

印尼拥有 700 多种语言 $^{10}$ ，其官方语言是印尼语，而印尼语是源于马来族语，是由 马来语演变出来的语言。当然, 作为印尼华人, 除了说印尼语外, 有不少华人也会说 自己的汉语方言和华语，这说明了印尼华人富于语言天赋，掌握了至少两种语言。据 调查，华人常用的汉语方言有客家话、福建话（闽南语）、潮州话、海南话、广东话 (粤语) 等。为了解印尼华人的语言背景，本文使用问卷调查法，收集了 97 个问卷， 以下其结果:

\footnotetext{
${ }^{10}$ Hutapea, Erwin. (22 Februari 2020) .Indonesia Punya 718 Bahasa Ibu, Jangan Sampai Punah!. Kompas.com. Diambil dari https://edukasi.kompas.com/read/2020/02/22/21315601/indonesia-punya-718-bahasa-ibu-jangan-sampai-punah?page=all
} 


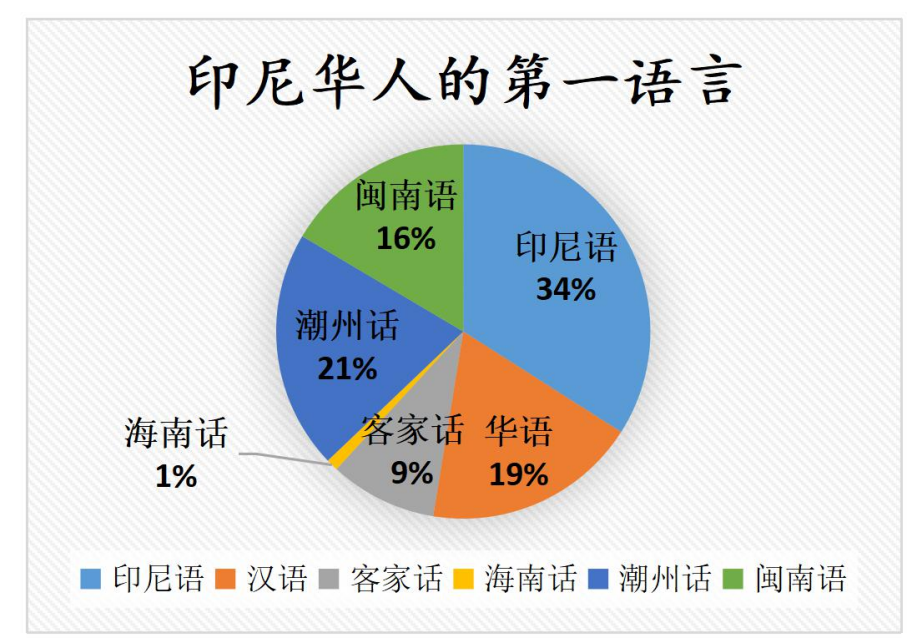

图 3-1 印尼华人的第一语言

从上图上可看，从 97 位，在沟通交流时他们都会说印尼语和华语，只不过在不同 的场合和不同的人使用不同的语言。除了问此题目外，本文也问他们，在与华人沟通 交流时你们常用什么语言。从问卷收集发现，有 33 位华人（34\%）日常生活中会说印 尼语，有 20 位华人（21\%）会说潮州话，有 18 位华人（19\%）会说华语，有 16 位华人 （16\%）会说福建话（闽南语）, 有 9 位华人（9\%）会说客家话，有 1 位华人（1\%）说 海南话。

语气词 [méh]源于哪个语言呢？据调查印尼华人所说的语气词 $[\mathrm{méh}]$ 不是源于普通 话, 也不是源于印尼语, 因为在印尼语中没有此词。从这里我们可以断定, 语气词 [méh] 不是源于印尼语。如果不是源于印尼语，如果从以上 97 位华人的语言背景中，我们可 以断定此词应源于印尼华人的汉语方言，因为在沟通交流中，华人也会使用汉语方言 进行交流。更有趣的是，在使用印尼语沟通交流时，他们也会使用语气词 [méh]表达语 气与感情, 比如: “Kita cuma bertujuh [méh]?”、“Eh ini masih boleh makan [méh]?”、 “Itu pas Qian Ren datang [méh]? ”。从这个例子看, 我们更能确定印尼说华语时所使 用的语气词 $[$ méh] 应是源于汉语方言。

为证明印尼华语语气词 [méh]的来源, 本文访问了 53 位印尼华人, 发现他们在说 福建话（闽南语）、潮州话、客家话的时候会使用语气词 [méh]。为更深入了解此词, 本文通过观察、Whatsapp 语音录音和录视频调查他们的语言状况。以下其例: 
2021 年 1 月 16 日, 我们观察了印尼华人说福建话, 在交谈中我们发现, 在说福建 话时, 他们会使用语气词 [méh]。例如: “Yi ciak liao [méh]?”，意思是说 “你吃 了 [méh]？”。通过此句子可证明印尼福建华人在说福建话时会使用此词。

此外，2020 年 12 月 7 日，本文的朋友收到Whatsapp 语音消息，发 Whatsapp 语音 消息的是她爸爸。发 Whatsapp 语音消息的时候, 她的爸爸正因为某事而发怒, Whatsapp 语音消息里面的谈话是使用了潮州话，爸爸说： “Niama ane khuang chong tong le boi hiao chua yi [méh]? Le boi hiao kak yi ta [méh]? ”，其意思是 “你妈这么冲动 你不能劝他 $[\mathrm{méh}]$ ? 你不能跟他说 $[\mathrm{méh}]$ ? ”。从这里可看, 潮州话里也有语气词 $[\mathrm{méh}]$ 。

还有，2021 年 2 月 12 日大年初一时，本文录了我们向父母拜年的视频。当弟弟向 父母拜年的时候，本文发现弟弟和妈妈在说客家话进行对话时也会使用语气词 [méh], 比如:

弟弟说: “Ngai jiu hok shu, mak emo tiam-tiam kong ngai kao game hoo." 妈妈说: “Mak jiu kong nyi [méh]?”

弟弟说： “Jiu."

上述谈话是说，弟弟说 “我有读书，妈妈不要一直说我玩游戏哦”。然后，妈妈 笑着回答 “妈妈有说你 [méh]？”。最后，弟弟就回答 “有”。通过此对话，可证明印 尼客家华人在说客家话时也会使用语气词 [méh]。

从上述分析可说明, 印尼华人说华语时所使用的语气词 [méh], 应是源于印尼华人 的汉语方言。由于在印尼福建话、潮州话、客家话中有语气词 [méh], 还有, 由于印尼 福建华人、潮州华人和客家华人在说自己的方言时常用此词，我们可以断定印尼华语 中的语气词 [méh] 应源于印尼华人的福建话、潮州话语客家话。换句话，印尼华语语气 词 [méh] 是源于印尼华人的汉语方言的福建话、潮州话与客家话。

\section{2 语气词 $[\mathrm{méh}]$ 的语法特点}

为了解印尼华语语气词 [méh] 中的语法特点, 本文从句类、语法结构以及语法功能 进行分析。以下其几个特点:

\section{（一）从句类看}

从句类看，印尼华语语气词 $[\mathrm{méh}]$ 常用在疑问句，比如：反问句、设问句、回声问、 附加问等。据调查，印尼华语语气词 [méh]可以充当设问句和反问句。 


\section{（1） 语气词 [méh]在设问句中}

设问句是明知故问的提问句形式，这种故意提问的目的是为了引起对方的注意力。 设问句最大的特点是提出问题之后，顺势提出自己的答语，是自己发问又自己回答的 疑问方式。以下是印尼华语语气词 [méh]使用在设问句的例子:

(1) 好像零食, 零食有湿的 [méh]? 只有其他的, 就是冰冻的。

(2) 有这样夸张 [méh]? 没有吧。

(3) 尤其他有工作, 晚上又要上学, 很忙, 还有时间看电视 [méh]? 我觉得没有吧。 例(1)的 “好像零食, 有湿的 [méh]? ” 是问题, 后面的 “只有其他的, 就是冰冻的” 是答语。在这个句子中，其实说话者心目中已经知道答案，零食没有湿的，只有冰冻 的。例(2)的 “有这样夸张 [méh]? ” 是问题，后面的 “没有吧” 是答语。在这个句子中, 可以知晓说话者自己认为此事没有那么夸张。例(3)的 “尤其他有工作，晚上又要上学, 很忙, 还有时间看电视 [méh]?”是问题, 后面的 “我觉得没有吧” 是答语。说话者觉 得对方的时间太紧，应该没有时间看电视了。

\section{（2） 语气词 [méh]在反问句中}

反问句是用反诘的形式来提问，这种问句形式其实没有真正的疑问，只是用疑问 形式曲折地表达自己对事情的看法，而且，在句子中已经隐含着答案，通常用肯定形 式表示否定的意思, 或者用否定形式表示肯定的意思。以下是印尼华语语气词 [méh]使 用在反问句的例子：

(1) 会辣 [méh]?

(2) 难道你星期天有上班 [méh]?

(3) 我刚才不是说了 [méh], 你忘了哈?

例(1)用的是肯定形式，其实这个句子要表示这种东西不辣，但是说话者不相信自 己，才提出反问 “会辣 [méh]?”。例(2)用的也是肯定形式，这句子要表示说话者向对 方表现否定，他觉得星期天没有上班，所以才提出反问“难道你星期天有上班 [méh] ? ”。 例(3)用的是否定形式，这句子要说明，其实他刚才已经说了，但是有可能对方没听见 或者忘了，所以，他就用反问句提问 “我刚才不是说了 [méh]，你忘了哈?” 为了强调 他刚才已经说了。 


\section{（二）从语法结构看}

问卷调查中，本文也设了几个关于语气词 $[\mathrm{méh}]$ 的句子，一共收回了 120 个句子。 那么, 为了解印尼华语语气词 [méh] 的位置, 本文分析了每一个句的结构。据分析, 语 气词 [méh] 的位置可以在名词、动词、形容词、代词和助词后面。以下其分析结果:

\section{（1）名词 $+[$ méh $]$}

印尼华语语气词 [méh]可以出现在名词的后面, 下面其例:

(1) 你没有带钱 $[$ méh]?

(2) 你没有去过新加坡 [méh]?

(3) 他不会说方言 $[$ méh]?

上述例子说明印尼华语语气词 [méh]可以与名词搭配，位置在名词的后面，其名词 由 “钱”、“新加坡” 和 “方言”。

\section{（2） 动词 $+[$ méh $]$}

印尼华语语气词 [méh]可以出现在动词的后面, 下面其例:

(1) 他有跟你讲 [méh] ?

(2) 今天他有来 $[\mathrm{méh}]$ ?

(3) 你不去 $[\mathrm{méh}]$ ?

(4) 是 $[$ méh]?

(5) 这样可以 [méh]?

上述例子说明印尼华语语气词 [méh] 可以与动词搭配，位于动词的后面。例(1)、(2)、 (3)的动词由 “讲”、“来”、“去” ，它们是表示动作的动词。例(4)的动词由 “是”， 这里的 “是” 能单独与语气词 [méh]来搭配来表示确认。例(5)的动词是 “可以”，它是 属于能源动词, 用来表示准许。

\section{（3）形容词+[méh]}

印尼华语语气词 [méh]可以出现在形容词的后面, 下面其例:

(1) 我说得流利 [méh]?

(2) 有那么厉害 $[$ méh]?

(3) 这个苹果真的这样贵 $[$ méh]? 
上述例子说明印尼华语语气词 [méh] 可以与形容词搭配, 位置在形容词的后面, 其 形容词由“流利”、“厉害”、“贵”。

\section{（4）代词+[méh]}

印尼华语语气词 [méh]可以出现在代词的后面, 下面其例:

(1) 他说的是这样 [méh]?

(2) 刚才你有来这里 $[\mathrm{méh}]$ ?

(3) 你要去那边 $[$ méh]?

(4) 你不认识他 $[$ méh]?

上述例子说明印尼华语语气词 [méh] 可以与代词搭配, 尤其跟指示代词和人称代 词, 位置在代词的后面。例(1)、(2)、(3)的代词由 “这样”、“这里”、“那边” ，按 照代词的分类它们都属于指示代词。例(4)的代词由 “他”，按照代词的分类 “他” 属 于单数的人称代词。

\section{（5） 助词 $+[$ méh $]$}

印尼华语语气词 [méh]可以出现在助词的后面, 下面其例:

(1) 我有说过 [méh]?

(2) 你做这件事了 [méh]?

(3) 你听说过 [méh]?

(4) 你吃饱了 [méh]?

(5) 你确定是他说的 [méh]?

(6) 你刚才不是说好要一起去的 [méh]?

(7) 不是你做的 $[$ méh]?

上述例子说明印尼华语语气词 [méh] 可以与助词搭配, 尤其是动态助词和结构助 词, 位置在助词后面。例(1)、(2)、(3)、(4)的助词是 “过” 和 “了”, 它们属于动态助 词。例(5)、(6)、(7)的助词是 “的”，是属于结构助词，表示状态或情况。

\section{（三） 从语法功能看}

从问卷调查、实地考察和访问调查本文发现, 印尼华语语气词 [méh]的语法功能主 要味蕾表示疑问的语气词, 当人们使用语气词 [méh]来提问的时候, 会表示各种各样的 疑问语气。本文认为印尼华语语气词 [méh]可以表示怀疑、可以表示不满意、可以表示 惊讶、以及可以表示反驳。以下其四个功能: 


\section{（1）表示怀疑}

印尼华语语气词 [méh] 最明显的功能就是对不确定真假的事请表示怀疑。以下是印 尼华语语气词 [méh]在表示怀疑的对话：

A：如果我们用酸奶 [kan], 用酸奶好像太浓 $[k a n]$, 就可以加点牛奶, 可是我是加 水 $[$ sih $] \ldots$

B：你不用加烧水这样 [méh]?

A：没有，不必加的，不必加。

上述对话说，如果放了酸奶还是太浓的话，可以加牛奶，但是在这时候说话者使 用的是水。看了说话者这么做，听话者就感到很好奇并怀疑对方的态度，就向说话者 提出疑问 “你不用加烧水这样 [méh]? ”。意思是说, 听话者认为这个东西应该加烧水, 但是说话者却没有加烧水。所以, 听话者因为心里起了怀疑心, 到底需不需要加烧水, 才向说话者提出疑问。通过听话者的反应可以得知，句子里面的语气词 $[\mathrm{méh}]$ 是用来表 示怀疑。

\section{（2）表示不满意}

除了表示怀疑之外，印尼华语语气词 [méh]的功能也可以用来表示对不符合心意的 事情感到不满意。例如:

$\mathrm{A}$ ：为什么我们男生那么喜欢被包扎（受伤）呀?

B：对！以前隔离（在佛堂住睡）的时候，气死人了，难道有那么严重 [méh]？何 必 坐在那儿摆美!

以上的对话告诉我们此词的用处可以表示不满意的语气。首先，说话者提问到 “为 什么我们男生那么喜欢被包扎（受伤）呀？”，说话者认为那里的男生比女生太虚弱 了，因为那时候很多男生受伤了，都被包扎。听话者听了之后，就赞成对方的意见， 还补充了几句话表示他的不满意。句中的 “难道有那么严重 [méh]?”是表示听话者对 话题里面的男生的不满意，他觉得其实那些男生不应该坐在那里摆美，也觉得他们那 些男生确实比女生太虚弱了。所以，听话者就使用这个疑问语气词来表示他的不满意。

\section{（3）表示惊讶}

在某种情况下，印尼华语语气词[méh]可以表示对某种事情感到惊异。例如:

A：不是叫我们录（视频）吗?

B：要录 (视频) [méh]? 
上面的对话是要表示印尼华语语气词 [méh]用在表示惊讶的语气。首先，说话者对 自己还不确定到底需不需要录视频，他就问：“不是叫我们录（视频）吗？”。听到 这个消息的听话者感到很惊讶，有可能他还没打听到这个消息，心里希望不必录视频。 为了确定对方所说的话他就反问：“要录（视频）[méh]?”。所以从 “要录 [méh]?” 的句子里, 句中的 $[\mathrm{méh}]$ 是表示听话者感到惊讶的语气。

\section{（4） 表示反驳}

在某种情况下，印尼华语语气词 [méh]可用来表示反对或不赞同某事。例如:

$\mathrm{A}$ ：你是潮州人哈?

B：潮州是什么？Tio ciu 哈? 不是。

A：所以呢?

$\mathrm{B}$ ：我是广东人。

$\mathrm{A}$ : 是吗?

B：嗯，但是我不会说广东话。

$\mathrm{A}$ ：哦？是你爸爸还是你妈妈？

B：爸爸 [1ah], 我们全部都跟爸爸的嘛, 难道有人跟妈妈的 [méh]? 没有 [lah], 姓是跟爸爸的，所以全部都跟着爸爸 [1oh].

以上面的对话来看, 两人正在谈关于他们自己的身份。首先, 说话者提问： “你 是潮州人哈? ”, 听话者就回答说, 他不是潮州人, 他是广东人, 但是不会说广东话。 其次, 为确定广东人是听话者的爸爸还是妈妈，说话者又提问 “哦，是你爸爸还是你 妈妈? ”。听了这个问题，听话者就认为我们全部的姓氏应该是跟爸爸的，他就反驳 说：“难道有人跟妈妈的 [méh]? ” , 在后面他还加上自己的看法, 他觉得姓氏不是跟 着妈妈的，而是全都跟着爸爸的。通过上面的对话可说明，当我们不赞同对方的意见 时，这个语气词 [méh]可用来表示反驳说话人的意见。

\section{3 影响印尼华人使用印尼华语语气词 [méh]的原因}

印尼华语语气词 [méh]的使用算是已广泛传播，使用此词的印尼华人也不少。虽然 有的人对印尼华语语气词 [méh] 只当做口语习惯，但使他们说此词一定有原因。在这一 点, 本文将影响印尼华人使用印尼华语语气词 [méh] 的原因进行探讨。影响印尼华人使 用印尼华语语气词 [méh]的原因由: 


\section{（一）语言环境的影响}

环境对一个人的生活有了巨大的影响，这里的环境指的是他们在日常生活中的沟 通交流范围。虽然华人在印尼生活，但因为华人和印尼本地人共存在同样的地区，华 人与其他印尼本地族肯定有接触的。因此，对于每天的沟通交流一定有所影响。

印尼华语语气词 $[\mathrm{méh}]$ 也是如此，本来此词是在汉语方言才有的词，是华人与华人 之间常用到的词，但是，因为生活在这种环境里，当华人之间说出这词的时候，都会 相互影响周围的人，甚至有少数非华人也会使用这个词。所以，本文认为语言环境是 影响人们使用印尼华语语气词 [méh]的原因之一。

\section{（二）语言习惯上的影响}

上述已谈过语言环境对印尼华人使用印尼华语语气词 [méh]的情况有所影响。本文 认为, 因为这种状况, 久而久之印尼华语语气词 $[\mathrm{méh}]$ 也耳濡目染, 慢慢就变成了一个 口头习惯。本文进行访谈的时候，发现有些人根本没意识到自己本身有说过此词，因 为听惯别人如此使用 [méh], 自己也受到影响, 所以带入到每天的日常用语, 说话的时 候就这样顺口说出来。因此，本文认为用语习惯影响了印尼华人使用印尼华语语气词 [méh] 的原因之二。

\section{（三）语言混用的影响}

因为生活在各种各样的生活背景，自然也影响了他们之间所使用的语言了。那么 彼此之间会出现什么样的语言呢?

Lily Thamrin 认为: “当两个不同语言的人要进行语言沟通时，自然会出现另一 种语言混合形式..... ${ }^{11}$ ”。本文赞同这个说法，这说法指明若使用两个不同语言进 行沟通交流的话，会导致语言混用的形式。这说法符合印尼华人在沟通交流中所使用 的语言，印尼华人进行沟通交流的时候常常把两种或两种以上的语言混用在一起，导 致在一个句子里出现了不仅仅一种语言，有可能两种或者两种以上语言形成的。

本文认为，印尼华人使用印尼华语语气词 [méh]的原因就是如此造成的。本文在调 查研究的过程中，发现印尼华人的语言混用有三种形式，如：印尼语和汉语方言混用; 印尼华语和汉语方言混用; 及印尼华语、印尼语、和汉语方言混用。下列其例子:

(1) Kita cuma bertujuh [méh]?

\footnotetext{
${ }^{11}$ Lily Thamrin. 语言接触与文登华人语言选择——以闽南话词汇为例. Jurnal Cakrawala Mandarin. 2018:49.
} 
(2) 他知道你家 $[\mathrm{méh}]$ ?

(3) 你不能开你的 kamera [méh]? （你不能开你的相机 [méh]?）

上述的例子我们可以看到，例(1)是印尼语和汉语方言里的语气词 [méh]一起使用; 例(2)是印尼华语和汉语方言里的语气词 [méh]一起使用; 例(3)是印尼华语、印尼语及汉 语方言里的语气词 [méh]一起使用。以上的描述可以知道, 语言混用是影响印尼华人使 用印尼华语语气词 $[\mathrm{méh}]$ 的原因之三。

\section{（四）社交媒体的影响}

如今，科技的发达带给了我们很多好处与方便，其中一个就是互联网上的社交媒 体。通过这个平台，人们都可以在社交媒体发放自己的看法、分享自己喜爱的事物、 宣传信息、在线聊天、做生意，等等。有了这个平台，人们获取和发布信息变得越来 越方便，无需耗费力气，只要有了社交媒体，我们所发的信息人人皆知。

对于印尼华语语气词 [méh] 的情况也是如此。据本文所收集的资料,在图 2-3 和 2-4 里，是指语气词 $[\mathrm{méh}]$ 在社交媒体的使用状况。虽然图片里的是马来西亚华人的账户所 发的帖子，但是本人认为可能有些人看到帖子上面所写的 “ [méh]”之后，就学会使用 它，带入到每天的日常用语里。因此，本文认为社交媒体是影响印尼华人使用印尼华 语语气词 $[\mathrm{méh}]$ 的原因之四。

\section{四 结论}

印尼华语语气词是印尼华人在沟通交流中用来表达整个句子的某种意义的语气 词，就如印尼华人在沟通交流中所说的印尼华语语气词 [méh]。在日常生活中印尼华人 说华语时会用语气词 [méh]进行交流。为了解印尼语华语语气词 [méh]背后所隐藏的东 西, 本文以语言学、华语学、词汇学、语法学为理论基础, 使用定性研究法对此词进 行深入的研究。

从研究结果中我们可以得出以下几个结论：（1）印尼华语语气词 [méh]的声调是 阴平调，类似于汉语普通话的第一声。我们将声调读得越拉越长，表示的怀疑感就越

大；（2）使用印尼华语语气词 [méh]多数印尼福建华人、客家华人、潮州华人等，使 用了达到 $82 \%$ ，从年龄上看，青年和中年华人常用此词；（3）印尼华语语气词 [méh] 多用在非正式的情况，正式的场合偶尔也会说，一般来讲在无意识的情况下会用此词。 
此外, 印尼华语语气词 [méh] 也可以出现在文字形式方面, 比如在 WhatsApp, Instagram 中;（4）印尼华语语气词 [méh] 语言于汉语方言, 是源于印尼华人的福建话、潮州话 和客家话；（5）印尼华语语气词 [méh] 是典型的疑问语气词，是用来表示提问的语气 词, 主要出现在设问句和反问句, 此外, 此词可以出现在名词词、动词、形容词、代 词和助词后面, 还有, 此词主要为了表达怀疑、不满意、惊讶和反驳;（6）影响印尼 华人使用印尼华语语气词 [méh] 的原因主要因为环境的影响、语言习惯上的影响、语言 混用的影响、社交媒体的影响。

目前, 研究印尼华语语气词的研究者极少, 本文希望通过此研究结果可以丰富印 尼华语研究，同时也可以为研究者提供有价值的资料。 


\section{参考文献}

[1]陈光辉. 现代汉越语语气词对比分析：博士学位论文. 福建：福建师范大学， 2015 .

[2]程祥徽，田小琳. 现代汉语. 香港: 三联书店（香港）有限公司，2014.

[3]词汇学研究浅谈 https://www.wenmi.com/article/pzeqmn046o5m.html

对外投资合作国别（地区）指南一一印度尼西亚.

http://www.mofcom.gov.cn/d1/gbdqzn/upload/yindunixiya.pdf

[4] 郭熙. 华语研究录. 北京: 商务印书馆, 2012.

[5]郭熙. 论祖语与祖语传承. 2017，第 3 期，总第 9 期.

[6] 郭士玉. 92 年出生者遇 “中年危机” ? 国内外划分标准不一. 新华网，2017-03-20.

[7]Harimurti Kridalaksana. Introduction to Word Formation and Word Classes in Indonesian.

Jakarta: Yayasan Pustaka Obor Indonesia， 2015.

[8]和平日报. 印尼中文报业的历史和前景. 和平日报，2015-12-02.

[9]黄伯荣，廖序东. 现代汉语（增订四版）（下册）. 北京：高等教育出版社， 2007.

[10]Hutapea, Erwin. (22 Februari 2020). Indonesia Punya 718 Bahasa Ibu, Jangan Sampai Punah!. Kompas.com. Diambil dari

https://edukasi.kompas.com/read/2020/02/22/21315601/indonesia-punya-718-bahasa-ib u-jangan-sampai-punah?page $=$ all

[11]Kusno. Pengantar Tata Bahasa Indonesia. Bandung: Rosda, 1985.

[12]李宇明. 论母语. 世界汉语教学. 2003，第 1 期，总第 63 期.

[13]李宇明. 大华语：全球华人的共同语. 北京：北京语言大学，2017.

[14]李云风. 现代汉语语气词 “哦”、“吆”、“咯” 的话语功能及其主观性研究：硕 士学位论文. 安徽大学, 2017.

[15]Lily Thamrin. 语言接触与文登华人语言选择一一以闽南话词汇为例。 Jurnal Cakrawala Mandarin.2018, Vol. 2, No. 2, PP. 45-55. E-ISSN 2579-4906.

[16]刘利, 李小军. 汉语语气词历时演变的几个特点. 北京师范大学学报, 2013 , 第 6 期，总第 240 期.

[17]刘月华，潘文娱，故桦.使用现代汉语语法（增订本）. 北京：商务印书馆，2016. [18]陆俭明. 关于建立 “大华语” 概念的建议. 汉语教学学刊, 2005. 
[19]Riki Nasrullah, Dadang Suganda, Wagiati. Interjeksi Ciye dalam Bahasa Indonesia: Suatu Kajian Morfologi, Sintaksis, dan Semantik. Fakultas Ilmu Budaya Universitas Padjadjaran. 2017.

[20]Rochmat Purnomo. Penggunaan Interjeksi Pada Percakapan di Whatsapp Grup Keluarga VII A SMP Negeri 2 Colomadu Kabupaten Karangayar. Surakarta: Universitas Muhammadiyah Surakarta. 2018.

[21]R.H. Robins. 普通语言学概论 General Linguistics. 北京: 外语教学与研究出版社, 2000.

[22]王宏亮. 现代汉语语气词 “呢”、“吧”、“啊” 的比较分析：硕士学位论文. 陕 西师范大学，2014.

[23] 王若江. 汉语正因教程. 北京：北京大学出版社，2005.

[24]王文斌. 从词汇研究走向词汇语义学研究. 中国英语教育, 2010, 第 1 期, 总第 27 期.

[25]Wedhawati. Tata Bahasa Jawa Mutakhir. Yogyakarta: Kanisius, 2006.

[26] 习丹丹. 河北唐山方言语气研究：硕士学位论文. 河北: 河北师范大学， 2015.

[27]杨欣安. 现代汉语. 重庆：重庆人民出版社，1956.

[28]杨忠. 语言学概论一一学习指导. 吉林: 东北师范大学, 2006.

[29]张从兴. 华人、华语的定义问题. 香港: 语文建设通讯，2003，第 74 期.

[30] 中国社会科学院语言研究所词典编辑室. 现代汉语词典（第七版）. 北京. 2016.

[31]周荐. 现代汉语词汇学教程. 北京：北京大学出版社， 2013.

[32]周国光. 现代汉语词汇学导论.广州：广东高等教育出版社，2015.

[33] 庄国土. 轮东南亚华族. 世界民族，2003，第三期. 